\title{
Duct tape occlusion treatment increased resolution in common paediatric warts
}

\author{
Focht DR 3rd, Spicer C, Fairchok MP. The efficacy of duct tape vs cryotherapy in the treatment of verruca vulgaris (the
} common wart). Arch Pediatr Adolesc Med 2002;156:971-4.

\section{QUESTION: In patients with common paediatric warts, is duct tape occlusion treatment more effective than cryotherapy for improving wart resolution?}

\section{Design}

Randomised (allocation concealed*), blinded (clinicians), ${ }^{*}$ controlled trial with a follow up of $\leq 16$ weeks.

\section{Setting}

Madigan Army Medical Center, Tacoma, Washington, USA.

\section{Patients}

61 patients (age range 3-22 y) who had common warts. Exclusion criteria included immunodeficiency states; chronic skin diseases (eg, eczema or psoriasis); allergy to adhesive tape; warts located on the face, periungual, perianal, or genital areas; and previous cryotherapy for the same wart. Follow up was $84 \%$ (mean age 9 y, $51 \%$ girls).

\section{Intervention}

Patients were allocated to duct tape occlusion treatment for a maximum of 2 months or until resolution of the wart $(n=30)$ or cryotherapy every $2-3$ weeks for a maxi- mum of 6 treatments or until resolution of the wart $(n=31)$. Patients in the duct tape group received a supply of standard duct tape. The first piece of duct tape, cut as close to the size of the wart as possible, was applied to the wart in the clinic by nursing personnel and left in place for 6 days. After 6 days, the wart was debrided, and the tape left off over night and reapplied the next morning. Patients in the cryotherapy group received a standard application of liquid nitrogen to the wart for 10 seconds.

\section{Main outcome measures \\ Complete resolution of the wart being studied.}

\section{Main results}

More warts in the duct tape group than in the cryotherapy group had completely resolved at the end of the treatment period (table).

\section{Conclusion}

In patients with common paediatric warts, duct tape occlusion treatment was more effective than cryotherapy for improving wart resolution.

*See glossary.

\section{COMMENTARY}

Viral warts are common complaints. Although they are painful over a pressure point, the main reason for seeking treatment is cosmetic appearance. In addition to over the counter topical treatments, cryotherapy is available from physicians who widely believe that it is more effective. The trial by Focht $e t a l$ and the systematic review by Gibbs $e t$ al raise a number of methodological issues that have been discussed elsewhere. ${ }^{1-2}$ Both studies call into question the effectiveness of freezing warts with liquid nitrogen. Should physicians abandon cryotherapy?

In the trial, duct tape was found to be more effective than cryotherapy, but the absolute effectiveness of cryotherapy was difficult to determine because no placebo group was used. In the systematic review, the average placebo cure rates were $30 \%$ in the 17 trials that used a placebo group. Surprisingly little is known about the longer term natural history of viral warts. A study by Massing and Epstein of 1000 institutionalised children suggested that over two thirds of warts (single and multiple) disappeared without any form of treatment after 2 years. ${ }^{3}$ Similar 2 year clearance rates have been reported elsewhere, ${ }^{4}$ reinforcing the point that "no treatment" must remain a viable option to many patients, or that at least a "no treatment" group should be included in future clinical studies to assess the additional benefit of treatment.

Thirteen years ago, Glover commented in a review of warts that "the knowledge of the disease and its treatments is often inversely proportional to the frequency of the disease". The well done systematic review on local treatments by Gibbs $e t$ al confirms that little has changed since Glover threw down the gauntlet. The history of RCTs for viral warts is largely a shambles, characterised by a profusion of small poor quality studies that do not take several important factors into account. These include age of patient, location of the warts on the feet or hands, type of wart, duration of wart and previous treatment, source of participants (from primary or secondary care), as well as factors relating to the intervention such as timing, duration, and frequency of cryotherapy. Long term studies are needed to capture wart recurrences. ${ }^{1}$ Altman goes on to discuss design options for future RCTs, such as within patient comparisons and the importance of considering individual people and not warts as the unit of analysis. ${ }^{2}$ 


\title{
Review: common topical applications containing salicylic acid or lactic acid improve clinical cure in non-refractory viral warts
}

Gibbs S, Harvey I, Sterling J, et al. Local treatments for cutaneous warts: systematic review. BMJ 2002;325:461-4.

\author{
QUESTION: In healthy people with clinically observed viral warts, are common topical \\ treatments or cryotherapy more effective than placebo or no treatment for improving \\ clinical cure?
}

\section{Data sources}

Studies were identified by searching electronic databases that included Medline (1966 to May 2000), EMBASE/ Excerpta Medica (1980 to August 2000), and CINAHL (1982 to March 1999); hand searching 8 relevant journals; and by reviewing bibliographies of relevant articles. Experts in the field and pharmaceutical companies were contacted for unpublished studies.

\section{Study selection}

Studies in any language were selected if they were randomised controlled trials (RCTs) of local treatments (all topical, intralesional, and surgical treatments, including cryotherapy but not systemic or psychological treatments) in people with clinically observed non-genital viral warts.

\section{Data extraction}

Data were extracted on study setting, sample size, key components of the intervention, study quality and outcomes. The main outcome was clinical cure (defined as complete disappearance of elevated/warty skin) at the end of a treatment period.

\section{Main results}

50 RCTs met the selection criteria. Meta-analyses were done using random effects models. (1) Simple topical agents containing salicylic acid and/or lactic acid for 6-12 weeks (13 RCTs): meta-analysis of 6 RCTs showed that the cure rate was higher in the treatment group than in the placebo group (table). (2) Cryotherapy (16 RCTs): meta-analysis of 2 RCTs that compared cryotherapy with placebo showed that the groups did not differ for cure rate (table). (3) Intralesional bleomycin (4 RCTs): the only RCT that used participants as the unit of analysis showed that the bleomycin and placebo groups did not differ for cure rate (table). (4) Topical 5-fluorouracil (3 RCTs): the cure rate was greater in the 5 -fluorouracil group than in the placebo group in only
1 RCT that made the comparison (table). (5) Intralesional interferons (6 RCTs): meta-analysis of 3 RCTs that compared interferon $\alpha$ with placebo showed that the groups did not differ for cure rate (table). (6) Dinitrochlorobenzene (DNCB) (2 RCTs): meta-analysis showed that the cure rate was greater in the DNCB group than in the placebo group (table). (7) Photodynamic treatment (PDT) (4 RCTs): 1 high quality RCT reported that the cure rate was greater in the aminolaevulinic PDT group than in the placebo PDT group $(56 \%$ v $42 \%$ of warts, $\mathrm{p}<0.05$ ).

\section{Conclusions}

In healthy people with viral non-refractory warts, common topical applications containing salicylic acid and/or lactic acid are more effective than placebo for improving clinical cure. Evidence on the effectiveness of cryotherapy is inconclusive.

\section{Source of funding: Norfolk Health Authority UK.}

For correspondence: Dr S Gibbs, Ipswich Hospital NHS Trust, Ipswich, UK. sgibbs@fish.co.uk

\begin{tabular}{|c|c|c|c|c|}
\hline Comparisons & $\begin{array}{l}\text { Number of } \\
\text { RCTs } \\
\text { (number of } \\
\text { patients) }\end{array}$ & $\begin{array}{l}\text { Weighted } \\
\text { event rates }\end{array}$ & RBI (95\% CI) & NNT (Cl) \\
\hline $\begin{array}{l}\text { TSA or TLA } v \\
\text { placebo }\end{array}$ & $6(376)$ & $73 \%$ v $48 \%$ & $62 \%$ (24 to 113 ) & 5 (3 to 10$)$ \\
\hline $\begin{array}{l}\text { ILS bleomycin } v \\
\text { placebo }\end{array}$ & $1(31)$ & $94 \%$ v $73 \%$ & $28 \%$ (-8 to 78$)$ & Not significant \\
\hline T5FU $v$ placebo & $1(128)$ & $45 \%$ v $13 \%$ & $263 \%$ (80 to 631$)$ & 4 (3 to 6$)$ \\
\hline \multirow{2}{*}{ TDNCB v placebo } & $2(80)$ & $80 \%$ v 43\% & $83 \%$ (24 to 169$)$ & 3 (2 to 6$)$ \\
\hline & & & RBR & NNH \\
\hline $\begin{array}{l}\text { Cryotherapy } v \\
\text { placebo or no } \\
\text { treatement }\end{array}$ & $2(69)$ & $29 \%$ v $34 \%$ & $12 \%(-195$ to 74$)$ & Not significant \\
\hline $\begin{array}{l}\text { ILS interferons } v \\
\text { placebo }\end{array}$ & $3(150)$ & $31 \%$ v $34 \%$ & $13 \%(-33$ to 44$)$ & Not significant \\
\hline
\end{tabular}

COMMENTARY — continued from previous page

In the meantime, as we await better evidence, when faced with someone presenting with a wart, it may be prudent to first consider doing nothing given the high rate of natural resolution of some warts. Then we should try out treatments that are best supported by the available evidence base and those with the least propensity to cause harm, such as topical salicylic acid gels or duct tape. Cryotherapy could be reserved as a third option should these 2 fail.

Professor Hywel C Williams

Centre of Evidence-Based Dermatology, Queen's Medical Centre, Nottingham, England, UK

1 Ringold S, Mendoza JA, Tarini BA, et al. Is duct tape occlusion therapy as effective as cryotherapy for the treatment of the common wart? Arch Pediatr Adolesc Med 2002;156:975-7.

Altman DG Commentary: Systematic reviewers face challenges from various study designs. BMJ 2002;325:461

3 Massing AM, Epstein WL. Natural history of warts. Arch Dermatol 1963;87:306-10.

4 Williams HC, Pottier A, Strachan D. The descriptive epidemiology of warts in British schoolchildren. Br J Dermatol 1993;128:504-11.

Glover MG. Plantar warts. Foot Ankle 1990;11:172-8. 